Open Peer Review on Qeios

\title{
Wicked Problems need WKID Innovation: Innovation as a Process to Develop a Disruptive Technology Product
}

\author{
E. Natasha Stavros ${ }^{1}$ \\ 1 University of Colorado at Boulder
}

Funding: The author(s) received no specific funding for this work.

Potential competing interests: The author of the manuscript does business as (DBA) WKID Solutions providing educational resources and coaching services for inventors on topics unrelated to Earth System Science.

\section{Abstract}

\section{Now published in Research-Technology Management, https://doi.org/10.1080/08956308.2022.1994249}

Wicked problems result from complex systems and often have no single solution. WKID Innovation is a framework to tack wicked problems and is modeled after NASA's science system engineering. NASA is a leader creating disruptive technologies that alter the way that people, companies, or industries operate. It has been pioneering innovation to advance human knowledge since 1958 engineering the first human landing on the moon, successfully landing rovers on Mars, and leaving our solar system, literally going where no man has gone before. NASA drives innovation to new frontiers in our galaxy and beyond, while also collecting accurate, reliable Earth observations that change the way we live our life in the day to day. WKID Innovation is a framework to scale NASA processes for innovation, specifically by using the knowledge hierarchy to bridge design thinking and complex systems science to system engineer and manage disruptive innovation.

Keywords: innovation; NASA; information technology; process; wicked problem

\section{Introduction}

Companies seek to create entirely new markets through disruptive innovation that can change user and consumer behaviour. Consequently, innovation and disruption have become buzz words in recent history. In the modern era, innovation tends to leverage massive quantities of data collected from a multitude of sources. With so much data out there, how can we strategically invest to change people's behaviour while mitigating risks?

Changing people's behaviour and their associated organizational systems is not a well-constrained problem; it is a "wicked" problem. Wicked problems involve multiple organizations and often face disagreement about the causes and best solutions (APSC 2018). Such problems are resistant to 
resolution (Rittel and Webber 1973) and have no single solution, thereby require a systematic approach. While technology is thought to be only one driver of change, if designed and applied correctly, technology can enable systematic change for disruptive innovation. For example, most people would not choose to hitch-hike with a stranger a decade ago. However, a well-designed technology disrupted both the sociocultural status quo and policies to provide a tool for strangers to share rides, now a common practice.

Arguably, NASA is one of the first technology-based disruptive innovators in the world, pioneering innovation since 1958. For example, NASA engineered the first human landing on the moon despite only having 30 minutes of man hours in space at the time of US President John F. Kennedy's challenge in 1961 (Hero 2019). This was an engineering and management feat on par with other Man-Made World Wonders, so much so that 1968 Science magazine observed that: “NASA's “most valuable spin-off of all will be human rather than technological: better knowledge of how to plan, coordinate, and monitor the multitudinous and varied activities of the organizations required to accomplish great social undertakings." NASA continues to lead innovation to new frontiers in our galaxy and beyond, while collecting accurate, reliable Earth observations and developing technologies that change the way we live our lives in the day to day. As such, wicked problems are exactly the kind of problems that NASA works to solve.

WKID Innovation is a framework to generalize and scale NASA processes for innovation to new, nonaerospace domains. From the system engineering and management perspective, this paper describes the WKID Innovation process, the tools used to inform it, and illustrates practical application of it to the technology: Geospatial Imaging Spectroscopy Processing Environment on the Cloud (ImgSPEC). It provides a common, convergent framework that incorporates best practices across design thinking, complex systems science, data science including artificial intelligence, change management, technology transfer, and system engineering and management. In this paper, I start by first describing the NASA process for innovation (Section 2), then define and describe the WKID Innovation framework to generalize this process (Section 3). I provide a case study example for applying the framework (Section 4) and end with concluding thoughts for future applications (Section 5).

\section{NASA Process for Innovation}

What makes NASA one of the most well-recognized brands in the world? Its vision is to: "reach for new heights and reveal the unknown so that what we do and learn will benefit all humankind." It does this in a breadth and depth of space science including Earth science, planetary science, heliophysics, and astrophysics. NASA has 62 years of experience engineering mission systems, data systems and management systems.

How does it really become its vision? At present, it relies on the Decadal Surveys, which the US National Academies produces about every 10 years in each of the four major space disciplines. For these surveys, the National Academies solicit community input on the current state of understanding with respect to each of the four science areas. They then synthesize these inputs to outline goals and objectives for each of the domains in order to advance humanity's understanding in the next decade. NASA then uses this Decadal 
Survey to determine which missions to develop. For each mission, there is a detailed plan for how the mission will advance systematic understanding and how it will successfully deliver on time and on schedule.

This plan comes from mapping the needs outlined in the Decadal Survey to mission requirements by following the scientific method and using something called a Science Traceability Matrix (Table 1). A mission will select a single Decadal Survey goal for "revealing the unknown", and then create discrete objectives for meeting that goal. There can be many objectives for a single goal; for each objective add a row to the matrix. Each objective is generally met by testing a hypothesis. Each hypothesis can be broken down into what kinds of physical parameters are needed to test that hypothesis.

Table 1. The NASA Science Traceability Matrix used to define instrument and mission requirements in order advance humanity's scientific understanding of life's existence on Earth, our solar system, and beyond.

Table 1. The NASA Science Traceability Matrix used to define instrument and mission requirements in order advance humanity's scientific understanding of life's existence on Earth, our solar system, and beyond.

\begin{tabular}{|c|c|c|c|c|c|}
\hline $\begin{array}{l}\text { Science } \\
\text { Goals }\end{array}$ & $\begin{array}{l}\text { Science } \\
\text { Objectives }\end{array}$ & $\begin{array}{l}\text { Physical } \\
\text { Parameter } \\
\text { Observation }\end{array}$ & $\begin{array}{l}\text { Observable } \\
\text { Measurement } \\
\text { Requirement }\end{array}$ & $\begin{array}{l}\text { Instrument } \\
\text { Functional } \\
\text { Requirements }\end{array}$ & $\begin{array}{l}\text { Mission } \\
\text { Functional } \\
\text { Requirements }\end{array}$ \\
\hline $\begin{array}{l}\text { Direct } \\
\text { Quote } \\
\text { from } \\
\text { NASA } \\
\text { Decadal } \\
\text { Survey or } \\
\text { Science }\end{array}$ & $\begin{array}{l}\text { Determine if } \\
\text { hypotheses } \\
\text { from }\end{array}$ & $\begin{array}{l}\text { Properties } \\
\text { predicted to } \\
\text { differ due to } \\
\text { hypotheses }\end{array}$ & $\begin{array}{l}\text { Signals to } \\
\text { observe } \\
\text { properties } \\
\text { predicted to } \\
\text { differ due to } \\
\text { hypotheses }\end{array}$ & $\begin{array}{l}\text { Signal } \\
\text { characteristics: } \\
\text { e.g. Spectral, } \\
\text { Spatial, } \\
\text { Temporal, etc. }\end{array}$ & $\begin{array}{l}\text { Observation } \\
\text { Location, } \\
\text { Observation } \\
\text { Time, } \\
\text { Observation } \\
\text { Direction \& } \\
\text { Change }\end{array}$ \\
\hline Plan & $\begin{array}{l}\text { Level } 4 \text { Data } \\
\text { Product }\end{array}$ & $\begin{array}{l}\text { Level } 2 \text { \& } 3 \\
\text { Data Product }\end{array}$ & $\begin{array}{l}\text { Level } 1 \text { Data } \\
\text { Product }\end{array}$ & $\begin{array}{l}\text { Level } 0 \text { Data } \\
\text { Product }\end{array}$ & \\
\hline
\end{tabular}

For example, if we want to understand how life on earth persists under climate change (Goal), a discrete science objective could be: to determine if drought or if beetle kill is the driving predictor of tree mortality. To test this, we need to observe physical parameters of tree mortality, drought, and beetle kill. Unfortunately, these parameters are not measurable at large enough scales to test our hypothesis. Consequently, we need to derive information on tree mortality, drought, and beetle kill from what we can observe. We can observe solar reflectance off of the Earth surface, which we can derive from radiance measured by an imaging system (e.g., advanced camera) spanning the visible to infrared portions of the electromagnetic spectrum. From this, we can define instrument requirements needed to make the desired measurements and the conditions for making them - e.g., what time of day, how frequently, the spatial resolution at which to collect, etc. The conditions for making measurements become the mission's functional requirements. The common string tracing science to mission requirements is the data, and specifically the level of processing needed to interpret the data. NASA broadly defines the "level" of data based on the amount of processing required to get to that level of information. In this sense, the Science 
Traceability Matrix (Table 1) actually follows the knowledge hierarchy (Figure 1; Ackoff 1989).

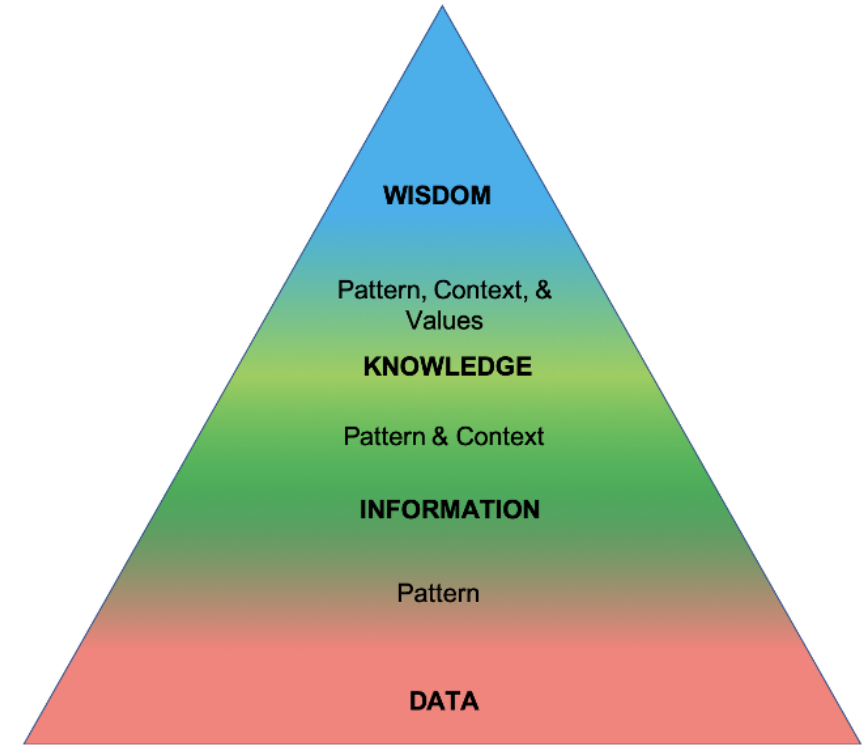

Figure 1. A representation of the Knowledge Hierarchy with an emphasis to systematically design a technology with intention of changing the current state (Wisdom) by advancing understanding (Knowledge) using Information derived from Data. Here L\# represents the NASA data product level as defined in Table 1.

Important to NASA realizing its vision to "reach for new heights and reveal the unknown", is the traceability from wisdom to data. Specifically, NASA maps science goals (Wisdom) to science objectives (Knowledge) and the key physical parameters (Information) needed to address those objectives, thereby informing the instruments and spacecraft build specifications for collecting Data. What makes this unique is that there is actually very little reference to wisdom in college textbooks (Rowley 2007). In fact, only three textbooks in a 2007 survey found mention of it. One of these textbooks defined wisdom as accumulated knowledge that enables application to new situations or problems (Jessup and Valcich 2008). By thinking of wisdom in this way, we can think of it as applied understanding (Aven 2013) or informed action. For example, we have a very deep understanding of gravity on Earth, so we can apply the concept of gravity in space or on Mars to inform how to land a Rover safely on the surface even under vastly different atmospheric conditions (Steltzner and Patrick 2016). This is what we call wisdom and it can help inform or change our actions. If we think of wisdom in this way, we can use the knowledge hierarchy as a framework to scale NASA processes for designing and developing "disruptive" missions to new technologies.

3. WKID Innovation: A Framework for designing disruptive technologies to solve wicked problems

WKID Innovation is framework to engineer change in complex systems with an emphasis on systematically designing disruptive innovation that changes actions. It is built on the foundational premise that human actions are determined by what we know to be true based on observations of our experience in the world. 
Specifically, informed action (Wisdom) is determined by values and the patterns of what we $\underline{\text { Know to be }}$ true within a given context based on the patterns of Information that we observe from evidence or the Data available. WKID Innovation uses best practices from system engineering, design thinking, the scientific method, and the knowledge hierarchy to mitigate risks while creating disruptive technology. WKID Innovation transcends any one discipline. In the realm of wisdom, it covers disciplines such as policy, economics, business, decision science, sociology, and psychology. In the realm of knowledge, it covers domain expertise and complex systems science. In the realm of information, it covers automation, machine learning, computer vision, image processing, mathematics, machine learning, signal processing, etc. And in the realm of data, it includes software and hardware engineering, ontologies, metadata and information security.

Because WKID Innovation covers such a breadth of topics, the success of WKID Innovation relies on system engineering. For this, we can think of the vee-model that describes how to system engineer a project (Fosberg and Mooz 1991). Mapping WKID Innovation to the vee-model results in systematically engineering a change in actions (Figure 2).

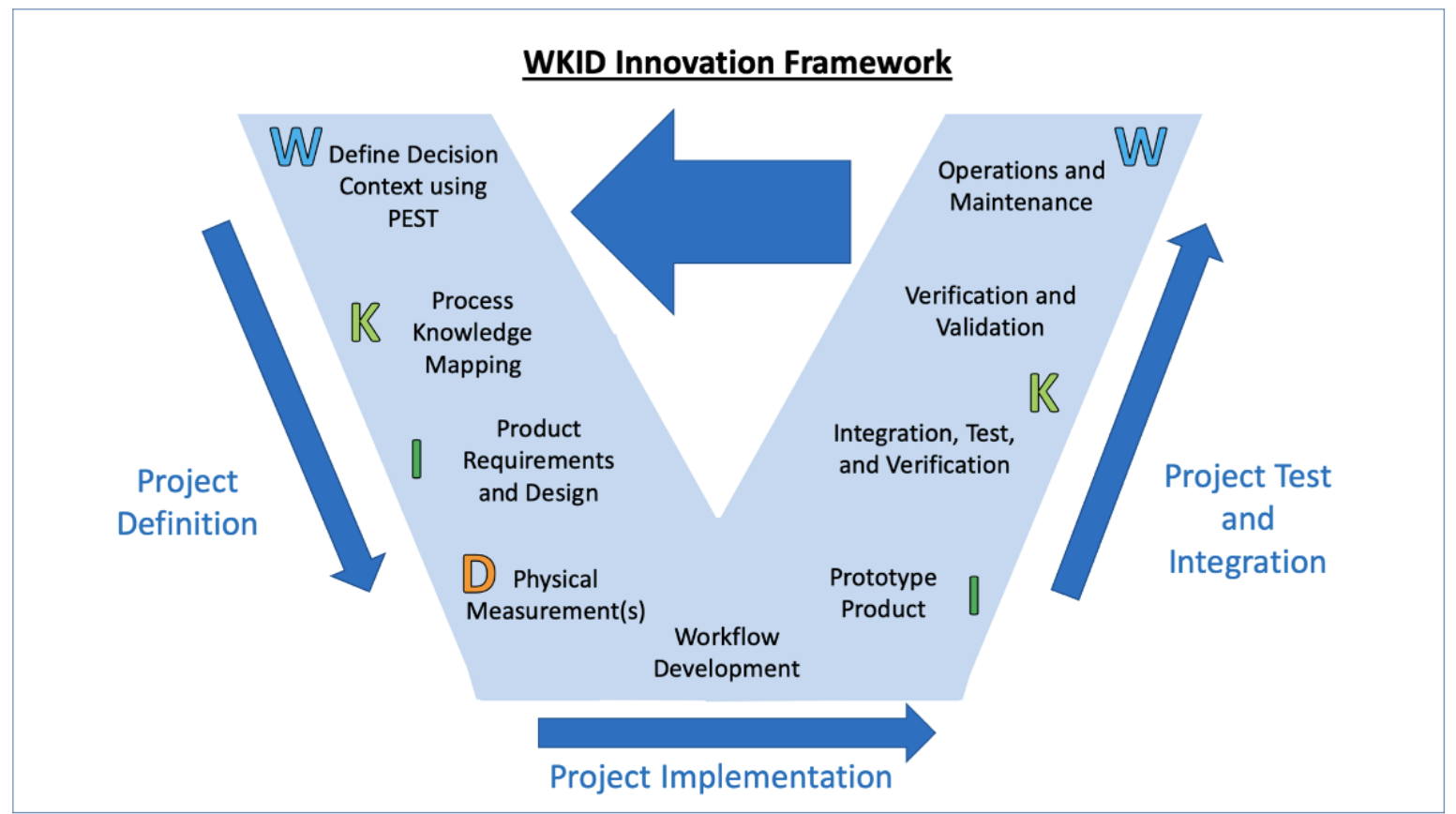

\section{Figure 2. Figure 2. The WKID Innovation framework, that adapts A representation of the vee-model approach to project system engineering with the knowledge hierarchy.}

The first step in applying WKID Innovation is to map the concept of operations, or informed actions (wisdom), of the current state to identify the opportunity for improvement. This can be really challenging, and for those with domain expertise it may seem an unnecessary step. However, if you want to change the current business environment with the adoption of a product (NRC 2004), you must understand the current business environment as it relates to Policy, Economic, Socio-cultural factors and Technology (PEST; Aguilar 1967). Thus, to identify a product for changing the current state, we must understand the 
informed actions by people and the processes that govern them. In fact, NASA's system engineering is defined as a disciplined approach for design, realization, technical management operations, and retirement of a system comprised of people, processes, hardware, software, and the interactions among them (NASA 2016); with people in policy, management ('economics'), management ('sociocultural') and technical fields (Forman 1993; Daniher and Cureton 1992).

Important to executing a change in the system is not only mapping the concept of operations, but also communicating and documenting a shared vision and implementation among the many players. To find a shared vision, we cannot simply ask people what they want, because as Steve Jobs once said, "people don't actually know what they want until you show it to them."

Rather we need to also examine the behaviours of the people in the system we want to change. In doing this, we can inform what we want to know that people can't or don't articulate. Mapping the policy and economics that govern people and the processes that define their interactions is founded in the foundational premise of WKID Innovation. The human brain follows the knowledge hierarchy by systematically processing data to motivate the actions we take. As you sit here, you read this, an action informed by you knowing that I have something to tell you, which you learned from information provided to you as words and sentences that your brain processed from data, photons reflected and absorbed from the screen/page.

To map peoples' behaviour so that we can define a shared vision for the opportunity of improvement, I have adapted the NASA Science Traceability Matrix (Table 1) into a Change Traceability Matrix (Table 2). By mapping the driving policy and economics that govern people and define their interactions, we document the decision context. From this, we use process knowledge mapping to translate their behaviours into the knowledge and information on which they rely as well as any available data (Figure 2). Then we can define our opportunity for improvement through product definition (Figure 2) and the metrics for evaluating that improvement. By doing this, we create clear traceability for the value add to the existing system that our opportunity would provide. For the NASA mission system, value add is validating that our integrated system can provide data to advance the current state of understanding. More broadly, this is commonly referred to as demonstrating the return on investment. Note that often people confuse "return on investment" with the "value of information" (Vol; Wilson 2015), however it is worth noting that while Vol is one metric of return on investment, it is not the only one (e.g., Brouseselle, Benmarhnia, and Benhadj 2016). 
Table 2. A Change Traceability Matrix helps to map the concept of operations of the current policy, economics, socio-cultural status, and technologies, while illuminating the opportunity for improvement and the metrics for evaluating return on investment.

Policy, Economics and Sociocultural factors that Process Knowledge Mapping govern people and the Technology (processes) that drive their interactions

\begin{tabular}{|c|c|c|c|c|c|}
\hline $\begin{array}{l}\text { Decision } \\
\text { Context }\end{array}$ & Decision & $\begin{array}{l}\text { Decision } \\
\text { Approach }\end{array}$ & $\begin{array}{l}\text { Reliant } \\
\text { Information }\end{array}$ & $\begin{array}{l}\text { Reliant } \\
\text { Data }\end{array}$ & $\begin{array}{l}\text { Opportunity } \\
\text { for } \\
\text { Improvement }\end{array}$ \\
\hline $\begin{array}{l}\text { Why is there a } \\
\text { decision to be } \\
\text { made? What } \\
\text { is the impact } \\
\text { of that } \\
\text { decision? } \\
\text { What are the } \\
\text { driving } \\
\text { motivations } \\
\text { (policy } \\
\text { mandate, \$, } \\
\text { etc.)? }\end{array}$ & $\begin{array}{l}\text { What is the } \\
\text { decision that } \\
\text { needs to be } \\
\text { made? Who } \\
\text { makes that } \\
\text { decision and } \\
\text { to whom are } \\
\text { they } \\
\text { accountable? }\end{array}$ & $\begin{array}{l}\text { Current } \\
\text { Technology/ } \\
\text { Tools used to } \\
\text { inform key } \\
\text { decisions }\end{array}$ & $\begin{array}{l}\text { What } \\
\text { information } \\
\text { is needed to } \\
\text { make a } \\
\text { decision and } \\
\text { requirements } \\
\text { on latency, } \\
\text { accuracy, etc. }\end{array}$ & $\begin{array}{l}\text { What data is } \\
\text { needed to } \\
\text { create that } \\
\text { info? Does } \\
\text { the data } \\
\text { science exist } \\
\text { to convert it } \\
\text { to } \\
\text { information? }\end{array}$ & $\begin{array}{l}\text { What are the } \\
\text { current } \\
\text { limitations? } \\
\text { What } \\
\text { improvements } \\
\text { could be } \\
\text { made? }\end{array}$ \\
\hline
\end{tabular}

Once we understand what the product needs to do based on what constitutes value add to the existing system, we need to define the requirements (Figure 2) by extending the Change Traceability Matrix (Table 2) into a Product Traceability Matrix (Table 3). Note that our goal in the Product Traceability Matrix (Table 3 ) is the opportunity for improvement as defined from the Change Traceability Matrix (Table 2). From this goal, we can define discrete objectives. These are usually something concrete that can be delivered that moves us towards our goal. For a big goal, like changing a system, there are many objectives. For each objective, add a row to the Product Traceability Matrix.

Table 3. A Product Traceability Matrix that maps the opportunity for improvement to product requirements.

\begin{tabular}{|l|l|l|l|l|}
\hline Goal & Objectives & Product Requirements & $\begin{array}{l}\text { Functional } \\
\text { Requirements }\end{array}$ & $\begin{array}{l}\text { Design } \\
\text { Requirements }\end{array}$ \\
\hline $\begin{array}{l}\text { Opportunity for } \\
\text { Improvement }\end{array}$ & $\begin{array}{l}\text { What } \\
\text { technology/ } \\
\text { Tool has } \\
\text { been } \\
\text { funded? } \\
\text { Discreet }\end{array}$ & $\begin{array}{l}\text { What are the conditions } \\
\text { under which the } \\
\text { technology/tool or } \\
\text { information adds value? }\end{array}$ & $\begin{array}{l}\text { What does the } \\
\text { product need to do } \\
\text { functionally to add } \\
\text { value? }\end{array}$ & $\begin{array}{l}\text { How does the } \\
\text { system need to } \\
\text { be designed? }\end{array}$ \\
\hline
\end{tabular}


identifying the conditions under which the product adds value; specifically, what it needs to do functionally, and the limitations or constraints on the design of the product. The Change Traceability Matrix (Table 2 ) can be used to define metrics for evaluating return on investment and informs the product, functional and design requirements. If the product does not have certain functionalities, then the benefits to using it will not be realized and it will not be adopted. In this way, the metrics for return on investment constitute a "performance floor" that stakeholders must have to make it worth the effort to adopt the product (Nash 2020). The design requirements should flow from the functional requirements, which should flow down from the product requirements. For example, if my software product needs to be used by millions, and I don't know how many people at any given time are going to use my system (function), then a design requirement would be to leverage elastic compute to avoid disruptions to operations.

Following the product life cycle (Figure 2), after we have a well-constrained problem space and product definition, we can actually build it, and verify and validate its value using our defined metrics for return on investment. After demonstrating the value add of our system, we can refine our concept of operations, growing the functionality of our system.

\section{Case Study: The Geospatial Imaging Spectroscopy Processing Environment on the Cloud (ImgSPEC)}

Here I provide an example of applying WKID Innovation to developing a prototype NASA data system of the future called the Geospatial Imaging Spectroscopy Environment on the Cloud (ImgSPEC). At present, NASA uses Science Data Systems to process raw signals from instrument measurements into physical parameters called Level 2 data products (Table 1). In this paradigm, there are barriers associated with prototyping algorithms that process data from raw instrument measurements to information used to test hypotheses and advance scientific understanding. According to Andrew Bingham, the JPL Instrument and Science Data Systems Section Manager, "In the era of big-data, algorithm developers require a full-scale data system to test and validate their algorithms. Such a system requires significant resources to implement and sustain, which can be a major barrier to small projects."

As such, the data system of the future would change how NASA processes data thereby reducing barriers to use and transforming how we live in the world today (e.g., respond to natural hazards, set crop prices, inform shipping and navigation, etc.).

To define what a data system of the future would be, we begin with the Change Traceability Matrix (Table 2): Decision Context. The most recent Earth Science Decadal Survey released in 2017(ESAS 2017) designated five Earth observations that were most highly recommended to change the current understanding of the Earth system. Of these, one of them was called Surface Biology and Geology (SBG), which should provide open data access of global imaging spectroscopy data at regular repeat intervals. Imaging spectroscopy provides unique, value-added information (Cawse-Nicholson, Townsend, and et al, n.d.) benefitting society (Lee et al., n.d.) by mapping the chemical fingerprints of the atmosphere and Earth surface. Imaging spectroscopy is also backwards compatible with the existing Landsat constellation (Seidel et al. 2018), which has proven invaluable over the past 30 years to governments, 
industry, science, and non-profits alike (Wu et al. 2019).

While there is a huge user base that already exists from the backwards-compatibility of the data, there are numerous barriers to realizing the full value of imaging spectroscopy data with new users. Specifically, imaging spectroscopy data has high dimensionality (Thompson et al. 2017), which results in large data volumes and processing needs with associated costs that could limit use. Moreover, imaging spectroscopy data requires specialized expertise in processing that may not be available to the breadth of users for which it could serve. SBG users span four major disciplines: biosphere (aquatic and terrestrial), hydrosphere, atmosphere, and mineralogy and range from the inexperienced to experienced user. Inexperienced users include managers, policy makers, and the general public who simply want synthesized information for situational awareness as events happen on Earth (e.g., mass tree mortality because of droughts), while experienced users include remote sensing algorithm developers.

Continuing to fill in the Change Traceability Matrix (Table 4), a key decision must address the design of a data system to maximize the utility of this data for as many people as possible. The present decision approach is that NASA missions deliver global, publicly-available data by producing quality data through Level 2 data products (Table 1) using an "80\% algorithm solution". The challenge is that NASA stops processing at Level 2, but advancing scientific understanding (Knowledge) and changing actions (Wisdom) requires Level $3+$ data (Table 1 ). Scientists have a saying that one spends $80 \%$ of their time processing data and $20 \%$ of their time actually analysing it; this $80-20$ division of labour actually emphasizes inhibition of scientific advancement. If we could change this rule so that we only spend $20 \%$ of our time processing the data and $80 \%$ analysing it, we could remove barriers and accelerate scientific advancement. Thus, we could establish knowledge so that it can be applied in new situations (Wisdom) and change how we live in the world.

\section{Table 4. Table 4. ImgSPEC example of the Change Traceability Matrix to define the problem space with clear traceability to the opportunity for improvement.}

\begin{tabular}{|c|c|c|c|c|c|}
\hline $\begin{array}{l}\text { Decision } \\
\text { Context }\end{array}$ & Decision & $\begin{array}{l}\text { Decision } \\
\text { Approach/ } \\
\text { Current } \\
\text { Technology }\end{array}$ & $\begin{array}{l}\text { Reliant } \\
\text { Information }\end{array}$ & $\begin{array}{l}\text { Reliant } \\
\text { Data }\end{array}$ & $\begin{array}{l}\text { Opportunity for } \\
\text { Improvement }\end{array}$ \\
\hline $\begin{array}{l}\text { Surface } \\
\text { Biology and } \\
\text { Geology - old } \\
\text { and new user } \\
\text { communities }\end{array}$ & $\begin{array}{l}\text { Maximize } \\
\text { data utility } \\
\text { by reducing } \\
\text { barriers to } \\
\text { entry }\end{array}$ & $\begin{array}{l}\text { Production } \\
\text { Environment } \\
\text { for standard } \\
\text { data product } \\
\text { workflows }\end{array}$ & $\begin{array}{l}\text { Generalized } \\
\text { user } \\
\text { workflows } \\
\text { from Level } 1 \\
\text { to Level } 2 \text { data } \\
\text { products }\end{array}$ & $\begin{array}{l}\text { Mission } \\
\text { Data and } \\
\text { Ancillary } \\
\text { Data }\end{array}$ & $\begin{array}{l}\text { Flip the } 80-20 \\
\text { division of } \\
\text { labour, which } \\
\text { inhibits scientific } \\
\text { advancement }\end{array}$ \\
\hline
\end{tabular}

Now that we have identified the goal to change the way that we do science, we need to define a discrete path forward. We can break this goal down by moving the opportunity for improvement from our Change Traceability Matrix (Table 4) into the first column of our Product Traceability Matrix (Table 3). In so doing, we define a product, in this case a prototype data system called ImgSPEC. Important to the success for 
technology transfer is rapid prototyping (NRC 2004). Therefore, the ImgSPEC prototype is initially designed to support a subset of users in terrestrial ecology, but is intended to be scalable to the population of potential users. Thus the objective (Table 3 ) is that: ImgSPEC should expand the use of existing imaging spectroscopy data by developing an on-demand science data system for distributing standard and custom Level $2+$ data products for the terrestrial ecology discipline.

To define the functional requirements, we conducted a series of interviews across the range of user experience levels to collect user stories (Wautelet et al. 2014). These user stories included the processing steps and pain-points associated with working with imaging spectroscopy data. These were then mapped to desired functionalities of ImgSPEC and prioritized by frequency of need (Stavros et al. 2020). Mapping functionality needs resulted in three ImgSPEC use cases: 1) a standard product, 2) custom parameterizations of a standard algorithm, and 3) model development for generating products of value that others may want. We also used these interviews to inform which metrics we should be tracking to determine return on investment. For example, users would be more inclined to use our system if it: 1) reduced download times, 2) provided easy provenance for reproducibility, and 3) enabled a scalable work environment from small to big jobs. As such, the metrics to determine return on investment of ImgSPEC include reduced download times, reproducibility of other users' code, and ease of algorithm deployment at scale.

From our objective, we can now clearly trace between our goal and a product that will provide value-add to the existing system. We define the product using Product Requirements:

- When imaging spectroscopy data are available, ImgSPEC shall enable users to process a standard product, custom parameterization, or develop/implement their own algorithms over a desired area and time.

- ImgSPEC shall include a documentation approach (metadata) to maintain provenance of on demand user workflows and enable reproducibility.

- ImgSPEC shall be open source and archive ImgSPEC software to make it publicly available.

Next, we map user workflows to product components in a ImgSPEC Concept of Operations diagram (Figure 3 ) to define our functional and design requirements. We can then apply a hybrid waterfall-agile management approach to build and test the value add of our prototype before expansion to the larger SBG data system (NRC 2004). If ImgSPEC successfully demonstrates reduced barriers to entry (e.g., decreased download times, easy provenance, and scalable work environments), then it may transition into an operational state with further revisions. Specifically, expansion of ImgSPEC would result in increased functionality for a broader user base. As such, we anticipate additional functionalities that will be needed for our system. While it would be nice to fund all new functionalities (Goal), realistically, we will have to prioritize developments (Objectives) and define another round of product, functional, and design requirements (Stavros et al. 2020). As the project grows in success, it will get pulled in more directions, thus illuminating the importance in a well-defined Change Traceability Matrix (Table 2), which anchors growth in the direction of the change we wanted to see (Opportunity for Improvement/Goal). 


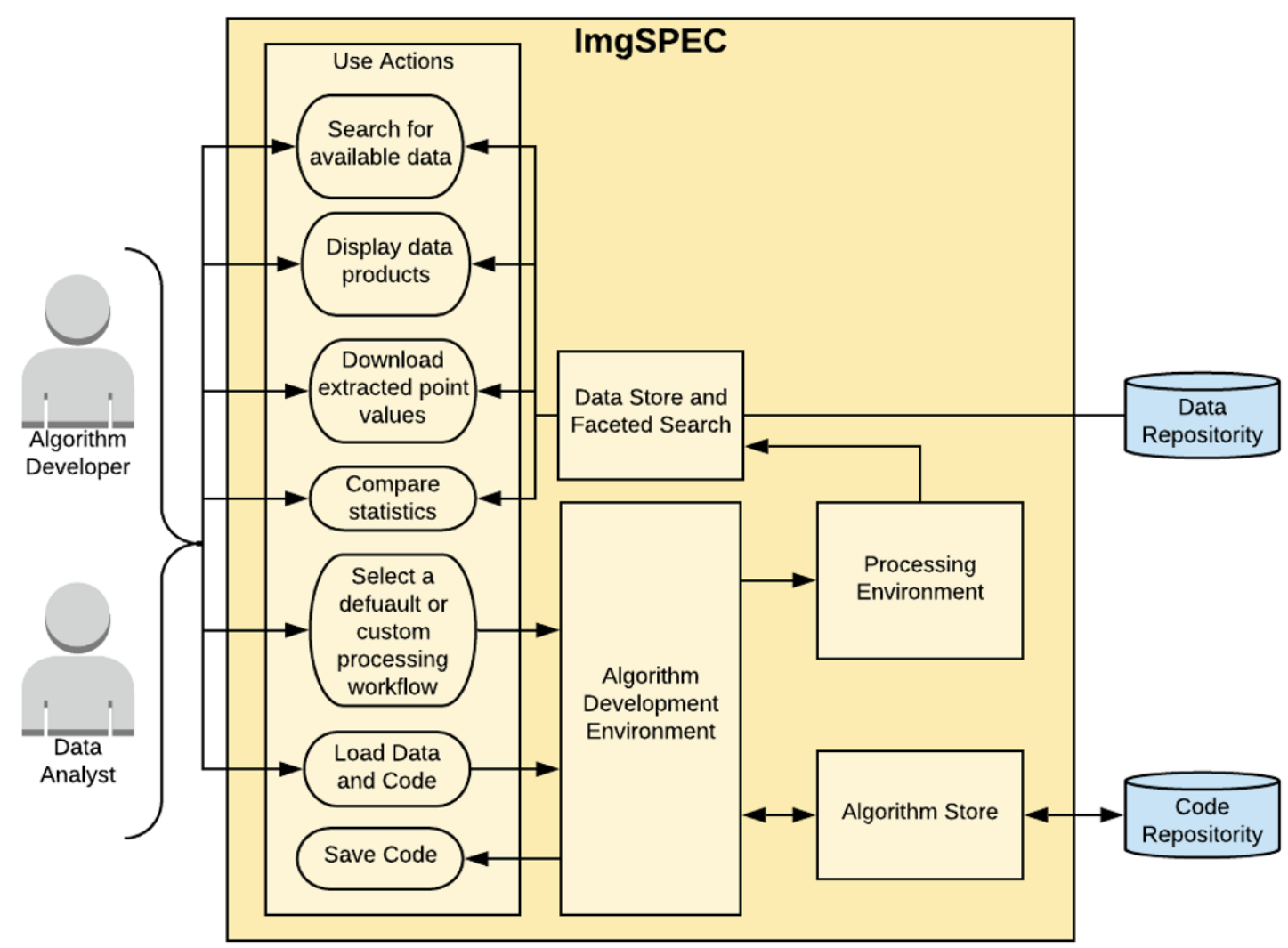

Figure 3. A simplified version of the ImgSPEC Concept of Operations to map user workflows to product components to define the functions that the system needs to add value.

\section{Conclusion}

WKID Innovation scales NASA processes for innovation to new, non-aerospace domains. It is unique in that it starts by purposefully designing a product from the beginning to affect change by focusing on "wisdom" and relying on the knowledge hierarchy to inform strategic investments based on systematic understanding. The emphasis on wisdom parallels the mindset of Design Thinking characterized by strong orientation to the unhidden and hidden needs of the stakeholders, prototyping, and divergent and subsequent convergent thinking (Brenner, Uebernickel, and Abrell 2016). A PEST analysis (Aguilar 1967) and the Change Traceability Matrix (Table 2) tool help illuminate hidden and unhidden functional needs of [a] product(s) by the many stakeholders. These functional needs can then trickle into product definition(s) through the Product Traceability Matrix (Table 3). In this way, WKID Innovation specifically addresses key limitations often inhibiting adoption of technologies, identified by the National Research Council as, “...the 
lack of information given to vendors about the relevant functional and technological needs... [rather than] strict adherence to detailed but incomplete specifications" (NRC 2004).

WKID Innovation, which maps the knowledge hierarchy to the project life cycle (Figure 2), is intended to facilitate prototype deployment and evolution. It is an iterative process that can be used at any phase of a project's life cycle and at any level of product development (i.e., prototyping through full-scale deployment). This iterative process enables consistent and constant validation of the value-add of the product being developed within the context of verifying the knowledge gain (NRC 2004) and subsequent change in actions.

Specifically considering divergent and subsequent convergent thinking, WKID Innovation facilitates coordinated, collaborative solutions to wicked problems. As such, WKID Innovation cannot be done in a vacuum. It provides a framework and tools (the Change Traceability Matrix and Product Traceability Matrix) to help document motivations and the functional needs across divergent views rather than dictate a single solution up front. In populating content into those tools, people can iterate divergent ideas on solutions into a convergent set of criteria by which to collaboratively define innovative solutions. This parallels the advice of former FBI hostage negotiator Chris Voss to "never split the difference," because solutions that require negotiation are not a compromise, they are a collaboration (Voss and Raz 2016).

Crucial to the effort of converging from divergent ideas, is efficient trade space exploration (Nash 2020). Regardless of how efficiently stakeholders can converge on a solution, it is worth noting that there is a lot of pre-work involved in understanding a complex system and this inherently takes time. For ImgSPEC, we have been working for 7 years to map the key players, their policies and financial models to inform a succinct problem definition and prototype solution that resulted in stakeholder buy-in to develop and build the prototype. While this process takes time, the advantage is that, by defining the problem space collaboratively with people, they feel heard and are more likely to "own" the result, proliferating its use and instituting the change the product hopes to accomplish.

When applying WKID Innovation, it is essential to periodically reassess if the opportunity for improvement in the Change Traceability Matrix (Table 2 ) is still valid for the current state and whether the defined product is still the most effective. ImgSPEC is only possible because of the advancements of many component technologies being developed over the last decade. As such, it is necessary to re-evaluate the Change Traceability Matrix periodically to determine how the landscape is changing so that innovation can adapt to the new environment.

Lastly, WKID Innovation is a process for strategic, systematic change management. According to the Oxford dictionary, to innovate is to "make changes in something established, especially by introducing new methods, ideas, or products." By extension, WKID Innovation is product-agnostic, whereby a product could just as easily be a bureaucratic or political process (new method) as an information technology (product) that has the ability to systematically change the way that we live in the world today.

\section{Acknowledgements}

The research was carried out at the Jet Propulsion Laboratory, California Institute of Technology, under a 
contract with the National Aeronautics and Space Administration (80NM0018D0004). @) 2021. California Institute of Technology. Government sponsorship acknowledged. ImgSPEC is funded under grant number AIST-18-0043 through the Advanced Information System Technology program. Table 2 is a modified version of the commonly used "Application Traceability Matrix" used by NASA and has been refined by the many working with the NASA Earth Science Division Applied Science Program. Finally, Figure 3 and the ImgSPEC concept is the product of input from the ImgSPEC team: Philip A. Townsend, David Thompson, Hook Hua, Sujen Shah, Winston Olson-Duvall, Thomas Huang, George Chang, Namrata Malarout, William Phyo, Brian Satorious, and Justin Merz.

\section{Declaration of Interests}

The author of the manuscript does business as (DBA) WKID Solutions providing educational resources and coaching services for inventors on topics unrelated to Earth System Science.

\section{References}

Ackoff, R.L. 1989. “From Data to Wisdom." Journal of Applied Systems Analysis 16.

Aguilar, Francis Joseph. 1967. Scanning the Business Environment. Macmillan Publishers Limited.

APSC. 2018. “Tackling Wicked Problems : A Public Policy Perspective.” 2018.

https://www.apsc.gov.au/tackling-wicked-problems-public-policy-perspective.

Aven, Terje. 2013. “A Conceptual Framework for Linking Risk and the Elements of the Data-InformationKnowledge-Wisdom (DIKW) Hierarchy." Reliability Engineering and System Safety 111: 30-36.

https://doi.org/10.1016/j.ress.2012.09.014.

Brenner, Walter, Falk Uebernickel, and Thomas Abrell. 2016. Design Thinking as Mindset, Process, and Toolbox: Experiences from Research and Teaching at the University of St.Gallen. Design Thinking for Innovation: Research and Practice. https://doi.org/10.1007/978-3-319-26100-3_1.

Brouseselle, Astrid, Tarik Benmarhnia, and Lynda Benhadj. 2016. "What Are the Benefits and Risks of Using Return on Investment to Defed Public Health Programs." Preventative Medicine Reprots 3: 135-38. Cawse-Nicholson, Kerry, Philip A. Townsend, and et al. n.d. "The World of Surface Imaging Algorithms: NASA's Surface Biology and Geology Designated Observable."

Daniher, C.E., and K.L. Cureton. 1992. “A Lifeboat for Space Station - The Assured Crew Return Vehicle (ACRV)." In IAF, International Astronautical Congress, 43rd, 12. Washington.

ESAS. 2017. “Decadal Survey: Thriving on Our Changing Planet: A Decadal Strategy for Earth Observation from Space." Washington D.C., USA. https://doi.org/10.17226/24938.

Forman, Brenda. 1993. "The Political Process in Systems Architecture Design." INCOSE International Symposium. https://doi.org/https://doi.org/10.1002/j.2334-5837.1993.tb01672.x.

Fosberg, Kevin, and Harold Mooz. 1991. "The Relationship of System Engineering to the Project Cycle." In INCOSE International Symposium: Session 5 The System Engineering Process. WIley.

https://doi.org/https://doi.org/10.1002/j.2334-5837.1991.tb01484.x.

Hero, Basil. 2019. The Mission of a Lifetime: Lessons from the Men Who Went to the Moon. Grand Central 
Publishing.

Jessup, Leonard, and Joseph Valcich. 2008. Information Systems Today: Managing Int He Digital World, 3rd Edition. Prentice Hall Press.

Lee, CM, EN Stavros, NF Glenn, J Luvall, C Hain, and S Uz. n.d. “Enabling Decadal Survey Applied Sciences Priorities during Earth Science Mission Pre-Formulation: A Case Implementation with Surface Biology and Geology."

NASA. 2016. “NASA System Engineering Handbook Revision 2.” NASA, 297.

https://www.nasa.gov/sites/default/files/atoms/files/nasa_systems_engineering_handbook_0.pdf. Nash, Alfred. 2020. “Efficient Trade Space Exploration.” IEEE, 1-6. https://doi.org/978-1-7821-2734-7. NRC. 2004. “Accelerating Technology Transition: Bridging the Valley of Death for Materials and Processes in Defense Systems." https://doi.org/10.17226/11108.

Rittel, H. W. J., and M. M. Webber. 1973. "Dilemmas in a General Theory of Planning." Policy Sciences 4 (2): 155-69.

Rowley, Jennifer. 2007. "The Wisdom Hierarchy: Representations of the DIKW Hierarchy." Journal of Information Science 33 (2): 163-80. https://doi.org/10.1177/0165551506070706.

Seidel, Felix C., E. Natasha Stavros, Morgan L. Cable, Robert O. Green, and Anthony Freeman. 2018. “Imaging Spectrometer Emulates Landsat: A Case Study with Airborne Visible Infrared Imaging Spectrometer (AVIRIS) and Operational Land Imager (OLI) Data." Remote Sensing Enivornment 215 (May): 0-1. https://doi.org/10.1016/j.rse.2018.05.030.

Stavros, E. Natasha, Catalina M. Oaida, Jessica Hausman, and Michelle Gierach. 2020. “A Quantitative Framework to Inform Cloud Data System Architecture and Services Requirements Based on User Needs and Expected Demand." IEEE ACCESS.

Steltzner, Adam, and William Patrick. 2016. The Right Kind of Crazy. New York, New York, USA: Portfolio/Penguin.

Thompson, David R., Joseph W. Boardman, Michael L. Eastwood, and Robert O. Green. 2017. "A Large Airborne Survey of Earth's Visible-Infrared Spectral Dimensionality." Optics Express 25 (8): 9186. https://doi.org/10.1364/OE.25.009186.

Voss, Chris, and Tahl Raz. 2016. Never Split the Difference: Negotiate as If Your Life Depended on It HarperCollins.

Wautelet, Yves, Samedi Heng, Manuel Kolp, and Isabelle Mirbel. 2014. “Unifying and Extending User Story Models." In CAiSE 2014: Advanced Information Systems Engineering, 211-25.

Wilson, Edward C.F. 2015. "A Practical Guide to Value of Information Analysis." PharmacoEconomics 33 (2): 105-21. https://doi.org/10.1007/s40273-014-0219-x.

Wu, Zhuoting, Gregory Snyder, Carolyn Vadnais, Rohit Arora, Michael Babcock, Gregory Stensaas, Peter Doucette, and Timothy Newman. 2019. "User Needs for Future Landsat Missions." Remote Sensing of Environment 231 (October 2018): 111214. https://doi.org/10.1016/j.rse.2019.111214. 
